suggestions covering five points, including the proposal for a Malaria Prevention Act to be passed by Parliament, might receive fuller appreciation if the author gave some figures stressing the gravity (or lack of it) of the situation.

Over the past 10 years the number of deaths reported in the United Kingdom as due to malaria was as follows: 1963,$4 ; 1969,9 ; 1970$, $5 ; 1971,9 ; 1972,7 ; 1973,5 ; 1974,2 ; 1975,5$; 1976,$3 ; 1977,7$.

During the first nine months of 1978 there were eight deaths related to 1533 cases of malaria imported into this country; of these, 201 cases were due to Plasmodium falciparum. The mean fatality rate of $P$ falciparum malaria notified in this country in the past decade is $4 \%$. This should certainly cause much concern since it reflects the delays in the diagnosis of the disease and also the shortcomings of prompt and adequate treatment of severe malaria.

No one will deny that these 64 deaths over the stated period are most regrettable and call for greater awareness of the danger of contracting malaria abroad and of the severity of the imported disease. The travel agencies in particular must recognise their special responsibility in this respect. The medical profession has been regularly informed of the problem by the Department of Health and Social Security but such educational activity could well be increased and widened. The World Health Organisation published recently a comprehensive document on malaria risk for international travellers and the ways to avoid it. This paper is obtainable from the WHO headquarters in Geneva on request. ${ }^{1}$

Whether the heroic measures outlined by Dr Hall are called for is a moot point, especially when we remember that motor accidents alone cause in England and Wales some 6000 7000 deaths every year, many of which are preventable by legislative or educational measures. I for one believe that the compulsory procedures advocated by $\mathrm{Dr}$ Hall, while understandable, are not necessary and some of them may be counterproductive or open to abuse and litigation. On the other hand much more effort should be made by the authorities and by the professional organisations to inform and advise everyone concerned.

World Health Organisation,

L J BRUCE-ChWATt

${ }^{1}$ World Health Organisation, Information on Malaria Risk for International Travellers. Reprinted from WHO Weekly Epidemiological Record. Geneva,

\section{African travel}

SIR,-We would like to comment on Dr S G Barber's preparations for a trans-Saharan expedition (5 August, p 404) and suggest some amendments.

Firstly, his choice of antibiotics lacks essential specificity. Typhoid fever must always remain a risk to the Saharan traveller despite immunisation. Even the acetone-killed vaccine does not provide complete immunity. It is therefore important to carry specific chemotherapy for the treatment of Salmonella typh $i$ infection. Full courses of chloramphenicol or co-trimoxazole should guarantee a complete cure, whereas ampicillin ensures only an $80 \%$ cure rate. ${ }^{1}$ Any trans-Saharan party should be aware that meningococcal meningitis epidemics are common and widespread in the savanna region of Mali, Upper Volta, Niger, and Nigeria in February, March, and April. It would therefore be wise for any traveller to receive prophylactic immunisation against the meningococcus before leaving Europe if travelling in the dry season. It would also be prudent to carry effective chemotherapy against a meningococcal infection. Ampicillin is not the drug of choice, whereas chloramphenicol has been shown to be as effective as benzylpenicillin in the treatment of meningococcal meningitis. ${ }^{2}$

Chloroquine is included only in tablet form. Vomiting and prostration may complicate acute malaria and the inclusion of injectable chloroquine would seem a sensible precaution.

If the party has female members clotrimazole vaginal tablets and cream would be indispensable. Personal hygiene may be difficult and hence vaginal candidiasis all the more likely, particularly if the lady is consuming $\mathrm{Dr}$ Barber's contraceptive pills.

In the unfortunate event of having to manage an unconscious fellow traveller no doctor should be without an airway. Another useful item is a pair of Spencer Wells forceps should the doctor have to attempt to deal with a torn major artery.

Finally, having included local anaesthetic, it is a pity that Dr Barber does not advocate its use in treating the excruciating pain following a scorpion bite.

D L CHILD

V M CHILD

Wusasa Hospital

C J TARRANT

Wusasa PA

' Chan, A C H, and Mak, M H H, Tropical Doctor, 1976, 6, 53.
Whittle, H C, al, British Medical fournal, 1973, 2 ,

\section{Childhood epilepsy}

SIR,-I fear that compression may have led Dr D P Addy in his article on childhood epilepsy (16 September, $p$ 811) to give advice on the dosage of paraldehyde which could be excessive. The dosage of $1 \mathrm{ml}$ per year of age may be well enough in the first two or three years of life, when admittedly most of these problems arise, but in an older child it could be excessive. On his own recommendation of $0 \cdot 15 \mathrm{ml} / \mathrm{kg}$ body weight this would give a $23-\mathrm{kg}$ 7 -year-old child a dosage of about $3.5 \mathrm{ml}$. The dosage of $1 \mathrm{ml}$ per year would give him $7 \mathrm{ml}$, while a 12-year-old would receive $12 \mathrm{ml}$, a dosage considerably in excess of the usual adult dosage.

ROBERT A SHANKS

Royal Hospital for Sick Children,

Glasgow

${ }^{*} *$ We sent a copy of this letter to Dr Addy, whose reply is printed below.-ED, $B M F$.

SIR,-Dr Shanks is, of course, right in pointing out that the traditional $1 \mathrm{ml}$ per year dose of paraldehyde is only really applicable to young children, who are the great majority of children with status epilepticus. The maximum dose should be $8 \mathrm{ml}(4 \mathrm{ml}$ in two different sites), and in older children it would be better to stick to $0 \cdot 15 \mathrm{ml} / \mathrm{kg}$. Paraldehyde is; however, a relatively safe drug and the dose of $1 \mathrm{ml}$ per year has been quoted in several leading paediatric texts for very many years without apparent dire consequences. Perhaps doctors in practice have more common sense than they are sometimes given credit for-I presume, for instance, that no one is going to employ all the measures listed in my article under status epilepticus at once but that they will be employed sequentially in resistant cases.

I am grateful, however, to Dr Shanks for pointing out the limitations of the $1 \mathrm{ml}$ per year aide-mémoire.

D P ADDY

Dudley Road Hospital,

Birmingham

\section{Paediatric anaesthesia}

SIR,-Your leading article (9 September, $p$ 717) on this subject illustrates an undesirable side effect of the policies and plans which so beset the hospital services. Why is it "clearly ... correct" to concentrate paediatric surgery in large centres? Are we to understand, for example, that infant craniotomies should not be performed in neurosurgical units or cleft lips repaired in plastic units and that orthopaedics, ear, nose, and throat, and eye work outside these paediatric centres should be confined to adult patients?

It is not disputed that it is vital to keep and continuously improve our children's hospitals of international standing, but the staff working in them should strive to avoid the degeneration from centres of excellence to centres of arrogance. It is one thing to have a few large hospitals dealing with the surgery and general management of life-threatening congenital abnormalities, quite another to argue that these are the only fit places to deal with the mass of more ordinary but interesting and varied clinical material that forms the bulk of children's work.

If this nonsense goes on small children's hospitals and the children's wards in district hospitals will get reorganised, reallocated, RAWPed up, normalised, rephased, or just plain closed. This will be to the detriment of all-parents, children, nurses, technicians, radiographers, physiotherapists, doctors, etcexcept presumably the hierarchy who make the decisions but don't actually deal with patients and their paediatric advisers who appear to regard themselves as the only people fit to deal with children.

J V I Young

St Mark's Hospital

London EC

\section{False-negative hypoglycaemic} screening test for patients in coma

SIR,-A 42-year-old known diabetic patient was brought to the hospital emergency department recently having been found cold, clammy, and: unconscious. A screening blood sugar estimation, performed by the nursing staff using the Reflomat method (Boehringer Corporation Ltd), showed an apparent blood glucose level of $4.0 \mathrm{mmol} / 1$ $(72 \mathrm{mg} / 100 \mathrm{ml})$. In the absence of other discernable causes for his condition a further blood sample was taken for subsequent laboratory analysis and $40 \mathrm{ml}$ of $50 \%$ dextrose was given intravenously. Consciousness was restored and the patient then gave a history of taking insulin without food. Analysis of the fluoride blood specimen by the Catalinks (Ames Co) glucose oxidase method showed that the true glucose level had been $0.6 \mathrm{mmol} / 1$ $(10.8 \mathrm{mg} / 100 \mathrm{ml}$ ) 